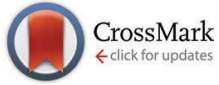

Cite this: Chem. Commun., 2014, 50, 11829

Received 18th July 2014, Accepted 19th August 2014

DOI: $10.1039 / \mathrm{c} 4 \mathrm{cc} 05545 d$

www.rsc.org/chemcomm

\section{Fingerprinting the tertiary structure of electroadsorbed lysozyme at soft interfaces by electrostatic spray ionization mass spectrometry $\dagger$}

\author{
Eva Alvarez de Eulate, ${ }^{a}$ Liang Qiao, ${ }^{b}$ Micheál D. Scanlon, ${ }^{b}$ Hubert H. Girault ${ }^{\star b}$ and \\ Damien W. M. Arrigan*a
}

Lysozyme can be electrochemically detected after adsorption at an electrified gel-water interface. Ex situ characterization by electrostatic spray ionization mass spectrometry provides insights into the interfacial detection mechanism by allowing changes to the tertiary structure of electroadsorbed lysozyme to be fingerprinted for the first time.

Adsorption of protein at the interface between two immiscible electrolyte solutions (ITIES) was first reported in 1984 by Vanýsek et al., when bovine serum albumin was observed to interfere with ion transfer across a water-nitrobenzene interface. ${ }^{1}$ Subsequently, several reports have addressed the electroactivity of biomacromolecules at the ITIES from different perspectives, e.g. mimicking the cell membrane, DNA hybridization, label-free detection and adsorption studies. ${ }^{2}$

Recently, electrochemistry of lysozyme (from hen egg white) at the ITIES was characterized by Scanlon et al., ${ }^{3}$ who proposed that its behavior comprised adsorption and facilitated ion transfer from the organic phase to the aqueous via interfacial complexation of the anion by the cationic protein. ${ }^{3}$ The proposed mechanism was exploited to achieve nanomolar limits of detection (LODs) for both lysozyme ${ }^{4}$ and haemoglobin ${ }^{5}$ in a label-free detection format. This consisted of pre-concentrating the protein at the gelled ITIES at its optimum adsorption potential, for a period of time, followed by stripping voltammetry.

The study of interfacial protein-anion complexes and interfacial adsorption at the ITIES is a challenging task. To date, predominantly electrochemical methods ${ }^{1,6}$ have been used to evaluate the capacitive properties of soft interfaces in the presence of adsorbed protein. However, information on the chemical

\footnotetext{
${ }^{a}$ Nanochemistry Research Institute, Department of Chemistry, Curtin University, GPO Box U1987, Perth, WA 6845, Australia.E-mail: d.arrigan@curtin.edu.au; Fax: $+61-8-9266-2300$

${ }^{b}$ Laboratoire d'Electrochimie Physique et Analytique, École Polytechnique Fédérale de Lausanne (EPFL), Station 6, CH-1015 Lausanne, Switzerland.

E-mail: Hubert.Girault@epfl.ch; Fax: +41216933667

$\dagger$ Electronic supplementary information (ESI) available: Materials and methods and control ESTASI-MS experiments. See DOI: 10.1039/c4cc05545d
}

composition of adsorbed layers at the ITIES, and in particular the nature of the tertiary structure of the interfacial protein after adsorption and interaction with the organic electrolyte anions, is not available from these methods.

Electrospray ionization-mass spectrometry (ESI-MS) is a highly sensitive strategy which can ionize macromolecules and provide information about protein molecular weight, tertiary structures, post-translational modifications, amino acid sequence and noncovalent interactions. ${ }^{7}$ Biphasic electrospray ionization (BESI)-MS was implemented to investigate non-covalent interfacial complexes that are formed at the ITIES between lysozyme and organic electrolyte anions ${ }^{8}$ as well as between peptides, such as melittin, ${ }^{9}$ and phospholipids. ${ }^{10}$ Recently, electrostatic spray ionization mass spectrometry (ESTASI-MS) was developed by Qiao et al. in a variety of experimental arrangements. ${ }^{11}$ The advantages of this technique over conventional ESI-MS include the ability to ionize analytes directly from a soft surface and to use a contactless approach, which avoids electrochemical reactions at the electrospraying electrode. ${ }^{12}$ ESTASI-MS has proven to be successful in the analysis of materials on the surface of, or within, a porous gel. ${ }^{13}$

Herein, we use ESTASI-MS to probe the tertiary structure of electroadsorbed lysozyme at the gelled ITIES as a function of surface coverage. This allows, for the first time, the detection of incremental changes in the degree of unfolding/folding of the protein with proximity to the interface. The interfacial surface coverage of electroadsorbed protein was varied incrementally by (i) increasing the applied interfacial potential, (ii) increasing the concentration of free lysozyme in the aqueous phase and (iii) applying longer pre-concentration times for the adsorption step.

Electroadsorption of lysozyme at a gelled ITIES with an estimated geometric area of $0.035 \mathrm{~cm}^{2}$ (assuming a perfectly hemi-spherical droplet of organogel at the tip of a glass pipette) was achieved by applying a set potential for a fixed pre-concentration time (Fig. 1 and Scheme 1). ${ }^{4}$ After pre-concentration of lysozyme at the gelled ITIES, the organogel was cut from the end of the glass pipette and fixed onto a $0.2 \mathrm{~mm}$ thick insulating plastic substrate (GelBond ${ }^{\mathbb{R}} \mathrm{PAG}$, Lonza). For ESTASI-MS analysis, the organogel was placed close to the MS inlet ("L" shaped ion transfer capillary) ${ }^{14}$ and a gold 


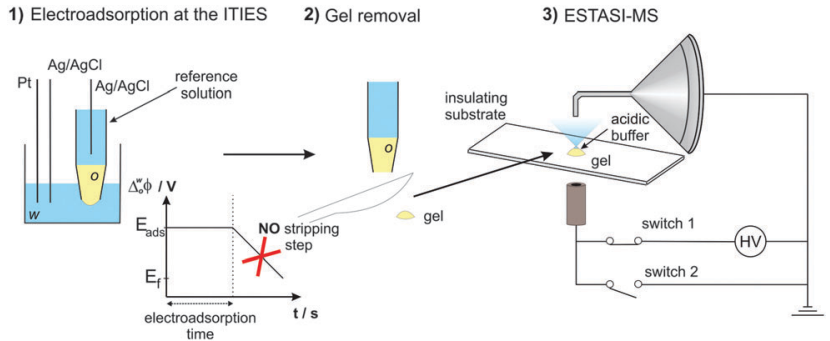

Fig. 1 Characterization of electroadsorbed lysozyme at the organogel (o)-water (w) interface via ESTASI-MS involves: (1) electrochemical preconcentration with a three electrode set-up, (2) gel removal from the glass pipette and (3) fixation of the hydrophobic gel on the insulating substrate for ESTASI-MS. Step 1 inset shows the onset potential applied for electroadsorption, $E_{\text {ads, }}$ similar to adsorptive stripping voltammetry (although no electrochemical stripping step is applied here).

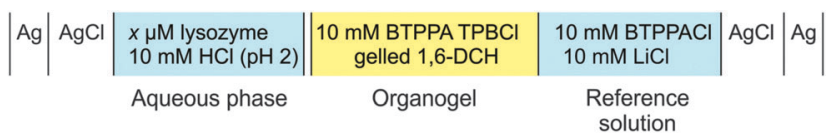

Scheme 1 Schematic of the electrochemical cell where $x$ is the concentration of lysozyme dissolved in the acidic aqueous phase.

electrode was positioned underneath the insulating plastic substrate. Drops $(1-2 \mu \mathrm{L})$ of an acidic solution $[1 \%(\mathrm{v} / \mathrm{v})$ acetic acid in 50:50 water: methanol (v:v)] were placed on top of the organogel. These drops of acidic solution enable protonation of the protein and also facilitate its transfer into the gas phase. Following the deposition of acidic solution, a pulsed direct current high voltage (see ESI $\dagger$ for more details) was immediately applied on the gold electrode to induce ESTASI for MS analysis of adsorbed proteins. ${ }^{13}$ Thus, this methodology uniquely enables the direct analysis of the electroadsorbed protein at a gelled ITIES. ${ }^{13}$

Prior to characterization of the organogel with electroadsorbed protein, separate control experiments were performed to identify the ESTASI-MS peaks of (i) the organic phase electrolyte salt bis(triphenylphosphoranylidene) tetrakis(4-chlorophenyl)borate (BTPPATPBCl) (Fig. S1, ESI $\dagger$ ) and (ii) lysozyme molecules at different concentrations in a drop of acidic solution (Fig. S2, ESI†).

Lysozyme has been reported to show several protonated states, depending on the unfolding conformation of the protein (i.e. tertiary structure) ${ }^{15}$ Higher charge states have been reported when the four disulfide bonds in lysozyme molecules were reduced by dithiothreitol, which leads to unfolding of the protein and consequent exposure of the chargeable residues buried within the protein's native compact structure. ${ }^{15 a}$ A study on lysozyme fibril formation reported protonated states of lysozyme with up to +15 charges when lysozyme was denatured at a low $\mathrm{pH}$ and high temperatures $\left(65{ }^{\circ} \mathrm{C}\right.$ for 14 and $\left.96 \mathrm{~h}\right) .^{15 b}$ These reports indicate that the lower charge states of lysozyme correspond to the retention of native conformation, whereas higher charge states indicate an increased degree of protein unfolding. Thus, it can be inferred that the lysozyme molecules, when sprayed directly from solution, retain their native configuration during ESTASI, as the dominant mass-to-charge ratio $(\mathrm{m} / \mathrm{z})$ values correspond to low charge states of the protein (Fig. S2, ESI $\dagger$ ). A final control experiment excluded the possible adsorption of lysozyme in the absence of an applied potential at the gelled ITIES. Immersion of the organogel in a $10 \mu \mathrm{M}$ lysozyme aqueous solution for 30 minutes at open circuit potential failed to produce a detectable protein signal in the ESTASI-MS spectrum (Fig. S3, ESI $\dagger$ ).

The surface coverage of electroadsorbed lysozyme at organogelwater micro-interface arrays is tuneable $e^{4}$ via the concentration of lysozyme in the aqueous phase ([lysozyme $\left.]_{\mathrm{aq}} / \mu \mathrm{M}\right)$, the preconcentration time applied $\left(t_{\text {adsorb }} / \mathrm{min}\right)$, and the magnitude of the interfacial applied potential $\left(\Delta_{\mathrm{o}}^{\mathrm{w}} \phi / \mathrm{V}(v s . \mathrm{Ag} / \mathrm{AgCl})\right)$. Surface

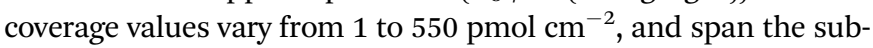
monolayer to $\sim 40$ monolayers surface coverage range. ${ }^{4}$ Hence, each of these controllable variables was used to systematically increase the quantity of lysozyme adsorbed at the interface and the resultant effects this had on the spectra following ESTASI were probed. Briefly, [lysozyme] aq. was varied from 0.5 to $5 \mu \mathrm{M}$ ( $t_{\text {adsorb }}=30 \mathrm{~min} ; \Delta_{\mathrm{o}}^{\mathrm{w}} \phi=1.0 \mathrm{~V}$, Fig. $\left.2 \mathrm{~A}\right), t_{\text {adsorb }}$ was varied from 5 to $30 \min \left(x=10 \mu \mathrm{M} ; \Delta_{\mathrm{o}}^{\mathrm{w}} \phi=1.0 \mathrm{~V}\right.$, Fig. $\left.2 \mathrm{~B}\right)$ and $\Delta_{\mathrm{o}}^{\mathrm{w}} \phi$ was varied from 0.8 to $1.0 \mathrm{~V}\left(x=10 \mu \mathrm{M} ; t_{\text {adsorb }}=30 \mathrm{~min}\right.$; Fig. $\left.2 \mathrm{C}\right)$. Immediately following electroadsorption, the organogel, plus any adhered protein, was removed from the cell and placed onto the insulating film for ESTASI-MS analysis. The ranges chosen for each parameter were previously shown to be suitable for studying the transition from low to high electrochemical detection signals as increased quantities of aqueous lysozyme adsorb and facilitate the transfer of the organic electrolyte anion, $\mathrm{TPBCl}^{-}$, across the interface. ${ }^{4}$ In this regard, the onset potential of $0.85 \mathrm{~V}(v s . \mathrm{Ag} / \mathrm{AgCl})$ for the detection of the first clear peaks in the ESTASI-MS spectra from the organogel (Fig. 2C) are in perfect agreement with the onset potential for substantive stripping peaks in our previous study.

Under conditions where prominent peaks were obtained in the spectra, each peak was assigned to one of the four charge states of the protonated lysozyme, as discussed above regarding the spectrum for an acidic solution of lysozyme following ESTASI. What is remarkable, however, is not that we can detect different charged states of lysozyme but that the relative intensities of these signals shift in a reproducible manner as the surface coverage of lysozyme was incrementally increased at the gelled ITIES. These trends are clearly highlighted in Fig. 2 with the $\mathrm{m} / \mathrm{z}$ values corresponding to [lysozyme $+10 \mathrm{H}]^{+10}$, [lysozyme $\left.+9 \mathrm{H}\right]^{+9}$, $[\text { lysozyme }+8 \mathrm{H}]^{+8}$ and [lysozyme $\left.+7 \mathrm{H}\right]^{+7}$ clearly labelled in each spectrum as a function of increasing surface coverage, i.e. as [lysozyme $]_{\mathrm{aq}}, t_{\mathrm{ads} s \mathrm{~b}}$ or $\Delta_{\mathrm{o}}^{\mathrm{w}} \phi$ were varied incrementally. The peak intensities were normalized by assigning a value of $100 \%$ relative intensity to the peak with the strongest signal in each spectrum. The lowest charge state (i.e. least unfolded), $[\text { lysozyme }+8 \mathrm{H}]^{+8}$, is entirely absent or of low relative intensity under conditions corresponding to low adsorbed lysozyme surface coverage but becomes the dominant signal at higher surface coverage. Conversely, the highest charge state (i.e. most unfolded), [lysozyme $+10 \mathrm{H}]^{+10}$, appears under conditions of low surface coverage but dramatically fades in prominence as the surface coverage increases. Finally, the intermediate charge state, 

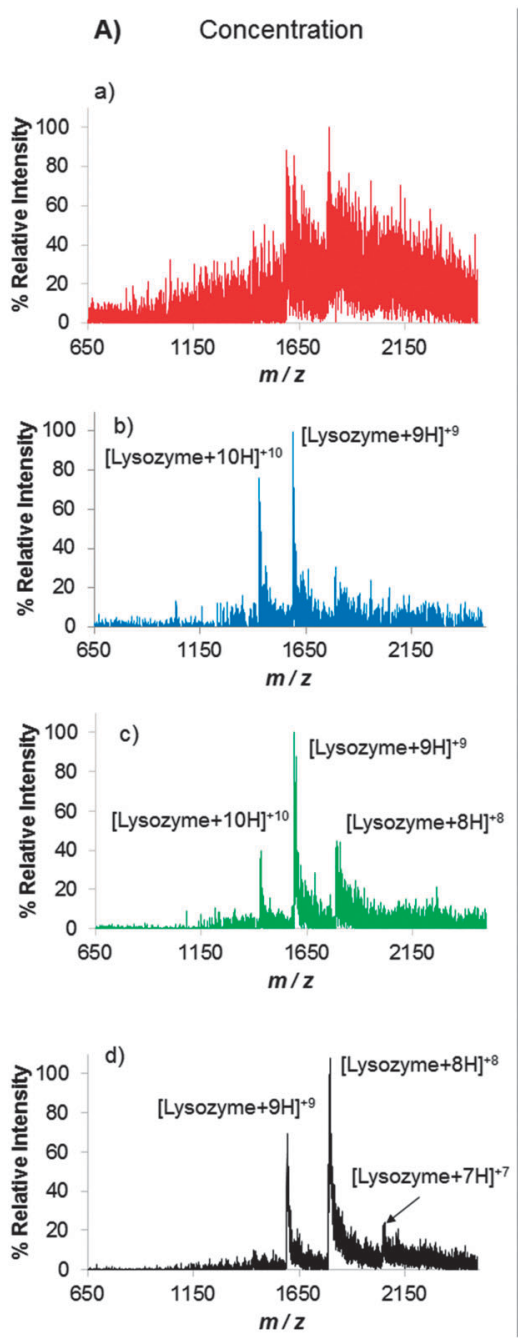

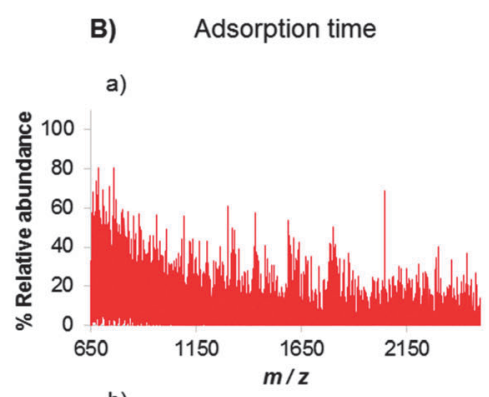

b)
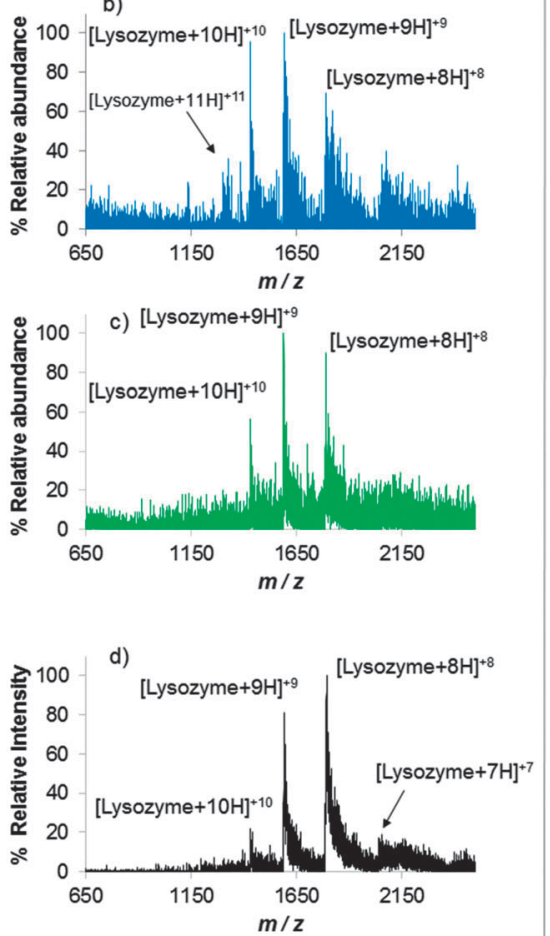

C) Applied potential
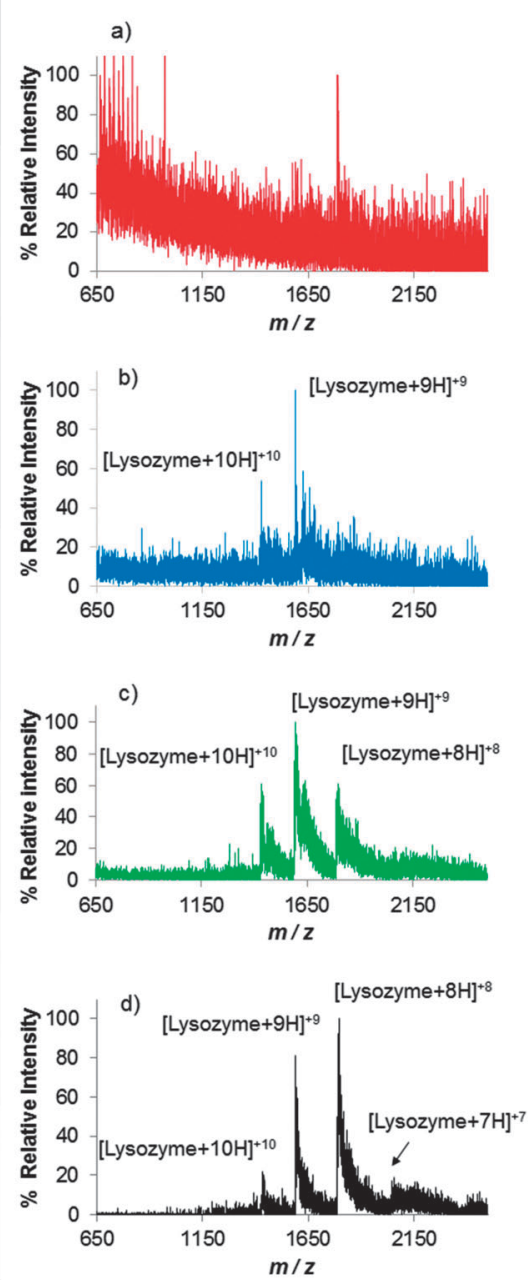

Fig. 2 Mass spectra obtained by ESTASI-MS from the organogel after: (A) electroadsorption of (a) 0.5, (b) 1 , (c) 2.5 and (d) $5 \mu$ M lysozyme (w) for

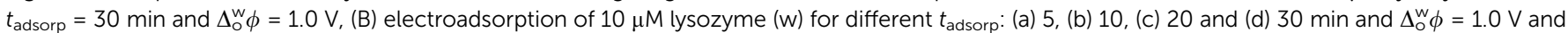
(C) electroadsorption of $10 \mu \mathrm{M}$ lysozyme (w) for tadsorp $=30 \mathrm{~min}$ at various interfacial potentials $\left(\Delta_{\circ}^{\mathrm{w}} \phi\right)$ : (a) 0.80 , (b) 0.85 , (c) 0.95 and (d) $1.0 \mathrm{~V}$. (w) refers to the aqueous phase and (o) to the organogel: $10 \mathrm{mM} \mathrm{BTPPATPBCl}$ in 10\% w/v PVC in 1,6-DCH.

$[\text { lysozyme }+9 \mathrm{H}]^{+9}$, also typically appears under conditions of low surface coverage and fades in prominence compared to the signal for [lysozyme $+8 \mathrm{H}]^{+8}$ with increasing surface coverage, but to a less dramatic extent than [lysozyme $+10 \mathrm{H}]^{+10}$. It is worth noting that even higher charge states, e.g. +15 charges, are only observable under extreme denaturing conditions leading to disulfide bond cleavage, which were absent in these experiments. Additionally, various [lysozyme] aq. were analyzed directly from the plastic film by ESTASI-MS. The data (Fig. S2, ESI $\dagger$ ) demonstrate that the changes in the spectra following electroadsorption (Fig. 2) were not a matrix effect due to the amount of protein analyzed.

Furthermore, the sensitivity of ESTASI-MS was investigated in terms of LODs in an attempt to characterize the interfacial coverage at the gelled ITIES. Picomole and femtomole amounts have been detected by chromatography-ESI-MS. ${ }^{16}$ Similarly, isoelectric focusing-ESTASI-MS, which is the closest experimental approach to that reported here, gave a LOD in the picomole range. ${ }^{17}$ If a monolayer of lysozyme (surface coverage: $13 \mathrm{pmol} \mathrm{cm}{ }^{-2}$ ) is adsorbed on the gel surface, then the total amount of lysozyme will be $0.45 \mathrm{pmol}$, assuming that a perfect hemispherical organogel area $\left(0.035 \mathrm{~cm}^{2}\right)$ is completely exposed to ionization. This means that a monolayer of lysozyme on the hemispherical organogel $(0.45 \mathrm{pmol})$ is below the LOD for this technique $(1.63 \mathrm{pmol}) .{ }^{13}$ As a result, detection by ESTASI-MS requires that multilayers of lysozyme are adsorbed; this is reflected in the high [lysozyme $]_{\text {aq. }}(0.5$ to $10 \mu \mathrm{M})$ and long $t_{\text {adsorb }}(30 \mathrm{~min})$ required before MS signals appear following electroadsorption (Fig. 2). Indeed, multilayer formation is corroborated from previous experimental data where the maximum surface coverage $\left(550 \mathrm{pmol} \mathrm{cm}^{-2}\right)^{4}$ calculated from the voltammetric desorption peak charge was 19 pmol of lysozyme ( $c a .40$ monolayers).

A clear image of the electroadsorption process for proteins at a gelled ITIES emerges when the trends in the change of the tertiary structure of adsorbed lysozyme with proximity to the gelled ITIES (Fig. 2) are taken into consideration with the demonstrable evidence for protein multilayer formation by ESTASI-MS 
and previous adsorptive stripping voltammetry studies. ${ }^{4}$ Firstly, lysozyme adsorbed in the monolayer directly in contact with the organogel is the most unfolded, with the highest charge. Secondly, lysozyme adsorbed in the outer layers becomes progressively more compact and less charged with increased distance from the gelled ITIES, eventually maintaining its native form. The outermost layer of lysozyme is adsorbed as its native form since it absorbs onto a barrier of other lysozyme molecules, thus not contacting the organogel or participating in facilitated ion transfer. These results are in agreement with observations from adsorption studies on solid substrates. ${ }^{18}$

Finally, it is interesting to note the complete absence of any prominent MS peaks due to complexation of $\mathrm{TPBCl}^{-}$by protonated lysozyme at the interface, as shown by previous BESI-MS studies. $^{8}$ The detection of these complexes was likely inhibited and below the LOD of ESTASI-MS due to (i) the buried nature of these complexes in the monolayers of lysozyme beneath the "native" lysozyme outer layers, and (ii) the viscous nature of the organogel onto which these complexes were adsorbed. In contrast, the outer layers of lysozyme were less tightly bound to the organogel, or buried, reflecting their dominance in the MS spectra.

Electroadsorption of biomacromolecules, such as the protein lysozyme, at soft interfaces (i.e. water/oil, ${ }^{3}$ water/gel ${ }^{4}$ or water/RTIL ${ }^{19}$ ) forms the basis of an emerging approach to sensitive biosensors that do not rely on electron transfer for signal generation. Herein, we showcase the capability of a recently developed ex situ technique, ESTASI-MS, to probe the nature of electroadsorbed lysozyme at a soft gel-water interface. In agreement with previous electrochemical studies, the application of ESTASI-MS indicated the formation of multilayers of adsorbed lysozyme at the soft interface. Multiplexing of electroadsorption and ESTASI-MS provides a unique method for fingerprinting the degree of unfolding of a protein's tertiary structure as a function of position within the adsorbed multilayer film (i.e. proximity to the soft interface). The inner layers, interacting closely with the soft interface, correspond to the most unfolded lysozyme conformation, while the outer layers, adsorbing onto previously electroadsorbed protein, present a more compact or "native" structure. Consequently, our findings provide a new level of detail on the nature of electroadsorbed biomacromolecules at soft interfaces and open up a new strategy to probe the tertiary structure of biomacromolecules that interact with soft interfaces. This is expected to impact biointerface development for diverse applications and to provide a new platform for mechanistic studies involving protein adsorption at soft interfaces.
E.A.d.E. acknowledges the award of a Curtin Strategic International Research Scholarship. Elena Tobolkina (EPFL) is kindly thanked for useful discussions.

\section{References}

1 P. Vanýsek, J. D. Reid, M. A. Craven and R. P. Buck, J. Electrochem. Soc., 1984, 131, 1788.

2 D. W. M. Arrigan, G. Herzog, M. D. Scanlon and J. Strutwolf, in Electroanalytical Chemistry, A Series of Advances, ed. A. J. Bard and C. G. Zoski, CRC Press, 2013, vol. 25, pp. 105-178.

3 M. D. Scanlon, E. Jennings and D. W. M. Arrigan, Phys. Chem. Chem. Phys., 2009, 11, 2272.

4 E. Alvarez de Eulate and D. W. M. Arrigan, Anal. Chem., 2012, 84, 2505.

5 E. Alvarez de Eulate, L. Serls and D. W. M. Arrigan, Anal. Bioanal. Chem., 2013, 405, 3801.

6 (a) A. E. Thomsen, H. Jensen, L. Jorgensen, M. van de Weert and J. Ostergaard, Colloids Surf., B, 2008, 63, 243; (b) G. Herzog, W. Moujahid, J. Strutwolf and D. W. M. Arrigan, Analyst, 2009, 134, 1608; (c) T. Osakai, Y. Yuguchi, E. Gohara and H. Katano, Langmuir, 2010, 26, 11530; (d) M. Y. Vagin, S. A. Trashin, S. Z. Ozkan, G. P. Karpachova and A. A. Karyakin, J. Electroanal. Chem., 2005, 584, 110; (e) P. Vanýsek and Z. Sun, Bioelectrochem. Bioenerg., 1990, 23, 177.

7 (a) R. Aebersold and D. R. Goodlett, Chem. Rev., 2001, 101, 269; (b) R. Aebersold and M. Mann, Nature, 2003, 422, 198.

8 R. A. Hartvig, M. A. Mendez, M. van de Weert, L. Jorgensen, J. Ostergaard, H. H. Girault and H. Jensen, Anal. Chem., 2010, 82, 7699.

9 M. A. Méndez, Z. Nazemi, I. Uyanik, Y. Lu and H. H. Girault, Langmuir, 2011, 27, 13918.

10 M. A. Mendez, M. Prudent, B. Su and H. H. Girault, Anal. Chem., 2008, 80, 9499.

11 (a) L. Qiao, R. Sartor, N. Gasilova, Y. Lu, E. Tobolkina, B. H. Liu and H. H. Girault, Anal. Chem., 2012, 84, 7422; (b) L. Qiao, E. Tobolkina, A. Lesch, A. Bondarenko, X. Zhong, B. Liu, H. Pick, H. Vogel and H. H. Girault, Anal. Chem., 2014, 86, 2033.

12 P. Liu, M. Lu, Q. Zheng, Y. Zhang, H. D. Dewald and H. Chen, Analyst, 2013, 138, 5519.

13 L. Qiao, E. Tobolkina, B. Liu and H. H. Girault, Anal. Chem., 2013, $85,4745$.

14 E. Tobolkina, L. Qiao, G. Xu and H. H. Girault, Rapid Commun. Mass Spectrom., 2013, 27, 2310.

15 (a) D. S. Gross, P. D. Schnier, S. E. RodriguezCruz, C. K. Fagerquist and E. R. Williams, Proc. Natl. Acad. Sci. U. S. A., 1996, 93, 3143; (b) M. Xu, V. A. Shashilov, V. V. Ermolenkov, L. Fredriksen, D. Zagorevski and I. K. Lednev, Protein Sci., 2007, 16, 815.

16 P. V. Bondarenko, D. Chelius and T. A. Shaler, Anal. Chem., 2002, 74, 4741.

17 (a) W. H. Zhu, J. W. Smith and C. M. Huang, J. Biomed. Biotechnol., 2010, 2010, 6; (b) S. Saraswat, B. Snyder and D. Isailovic, J. Chromatogr. B: Anal. Technol. Biomed. Life Sci., 2012, 902, 70.

18 (a) J. R. Lu, T. J. Su, P. N. Thirtle, R. K. Thomas, A. R. Rennie and R. Cubitt, J. Colloid Interface Sci., 1998, 206, 212; (b) E. A. Vogler, Biomaterials, 2012, 33, 1201.

19 E. Alvarez de Eulate, D. S. Silvester and D. W. M. Arrigan, Chem. - Asian J., 2012, 7, 2559. 